\title{
Treatment of panfacial trauma patient via submental intubation: a case report
}

\author{
Tae-Woong Ahn ${ }^{1}$, Kil-Hwa Yoo ${ }^{1}$, Min-Seok Oh ${ }^{1 *}$, Chul-Min Park ${ }^{1}$, Seong-Hoe Yoon ${ }^{1}$, Sun-Woong Yoon ${ }^{1}$, \\ Ka-Young Seol, Dong-Keun Lee ${ }^{1}$, Young-Ju Park², and Dong-Soo Shin ${ }^{2}$
}

${ }^{1}$ Department of Oral and Maxillofacial Surgery, Sun Dental Hospital, Daejeon 34813, Republic of Korea

${ }^{2}$ Department of Periodontology, Sun Dental Hospital, Daejeon 34813, Republic of Korea

(Received Jul 21, 2017; Revised version received Sep 29, 2017; Accepted Nov 11, 2017)

\begin{abstract}
Airway management in complex craniomaxillofacial trauma surgery is an important factor, and the choice of the intubation technique is often difficult and challenging. The choice of the intubation technique requires good assessment by the multidisciplinary team that includes maxillofacial surgeons and neurosurgeons as well as good communication between them. Submental intubation is a technique that is maintained extraorally after the conventional orotracheal intubation and the tube is extruded through the incision site in the submental region. It is a useful and safe airway management technique for craniomaxillofacial trauma surgery. It makes it possible to perform reduction of the nasal-orbital-ethmoidal complex fracture, and LeFort I, II, III fractures simultaneously. The aim of this study is to report a case of a craniomaxillofacial trauma patient who had an accompanying periorbital space abscess and treatment was performed by open reduction and internal fixation via submental intubation with a review of literature. After considering the method, complications and indications, we suggest this technique for safe and useful airway management of craniomaxillofacial trauma surgery.
\end{abstract}

KEY WORDS: Coronal incision, Free airway, Panfacial trauma, Periorbital space abscess, Submental intubation

\section{서 론}

두개안면부 복합 골절환자의 수술 시 기도유지는 중요한 사항이고, 어떠한 기도유지법을 사용할 지 선택하는 것은 고민스럽고 어려운 일이다. 삽관 술식의 선택은 구강외과 의사, 신경외과의사, 마취과의사를 포함한 전문적인 구성원 간의 긴밀한 의사소통과 협력을 필요로 한다.

대부분의 두개안면복합 골절환자의 경우 경비, 경구 삽 관에 제한이 따른다 $[1,2]$. 경비 삽관은 비골 골절의 경우 사용이 불가능하고, 뇌수막염 발생 가능성이 있고 두개저 골절환자의 경우 두개내로 튜브가 들어갈 위험이 있다. 또한 경구 삽관은 악간고정을 방해해서 상하악 골절 정복 시 안정성을 저해하므로 두개안면복합 골절 환자에서의 사용이 제한된다. 이러한 상황에서 기관절개 삽관술이 하

*Corresponding author: Min-Seok Oh

Department of Oral and Maxillofacial Surgery, Sun Dental Hospital, 645 Daejong-ro, Jung-gu, Daejeon 34813, Republic of Korea

Tel.: +82-42-251-5000, Fax: +82-42-257-2280

E-mail: omin333@naver.com
나의 대안으로 고려되어 왔으나 기관 협착, 성대 손상, 피 하 기종, 갑상선 손상 가능성 등의 단점이 존재한다[3,4]. 이러한 단점을 보완하고 술후 합병증이 적은 이하 삽관술 에 대해 고려해보았고, 본 증례의 환자의 기도 유지법으 로 사용되었다. 이하 삽관술은 통상의 경구 삽관술 후 이 부 저에 구강 저를 관통하는 절개 및 둔박리 후 관을 절 개부위를 통해 구강 외로 빼내어 유지하는 술식으로, 두 개안면복합 골절 환자의 기도유지에 유용하고 안전한 방 법으로 기관절개술의 대안으로 1986년 Altemir로부터 처 음 소개되어 변형을 거쳐 오늘날까지 수많은 두개안면복 합 골절환자에서 사용되어 왔다 $[5,6]$. 또한 비골안와사골 복합골절, LeFort I, II, III 골절 환자를 동시에 정복할 수 있게 해준다.

이에 본 연구에서는 안와주위간극 농양을 동반한 두 개안면복합 골절환자를 신경외과와의 협동 수술로 이하 삽관술을 통해 관혈적 정복술 및 내고정술로 치료한 예 를 문헌고찰과 함께 보고하고, 술식과 수술 후 합병증, 적응증 등에 대해 고찰해 봄으로써 향후 두개안면복합 골절 환자의 기도 유지에 유용한 치료법을 제시하고자 한다. 


\section{증례 보고}

추락으로 수상한 41세의 남자환자가 본원 응급실에 내 원하였다. $\mathrm{Lab}$ 검사 결과 $\mathrm{CRP}$ 가 18.75 로 상승하였고, 우 측 안구의 눈꺼풀 부종, 결막 부종, 안구돌출, 시력저하, 안 구운동 장애를 호소하였고, 우측 안와주위간극 농양이 (Fig. 1) 발견되어 수술 전 응급 절개 및 배농술을 시행하 였다.

임상 및 방사선 검사를 시행한 결과 전두골의 분쇄골절, LeFort I, II, III급 골절, 비골안와사골 복합체 골절을 포함

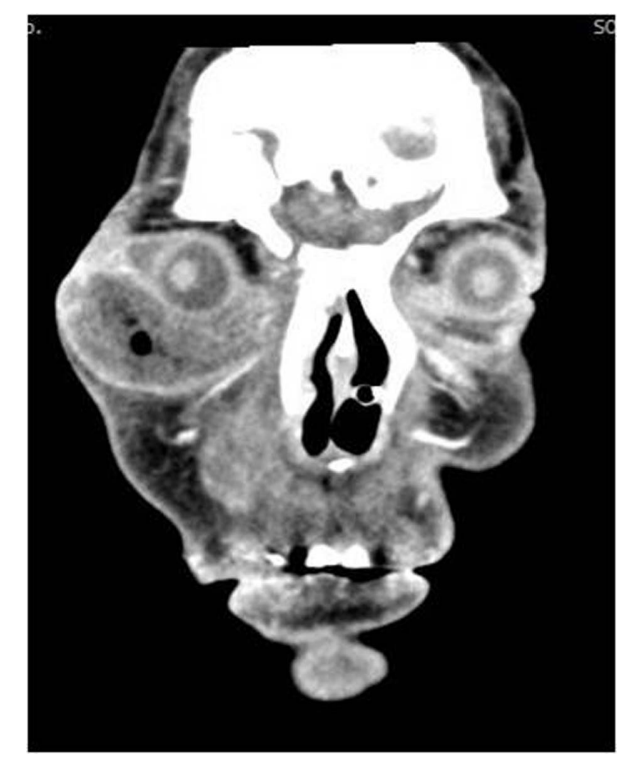

Fig. 1. Right periorbital space abscess was detected.

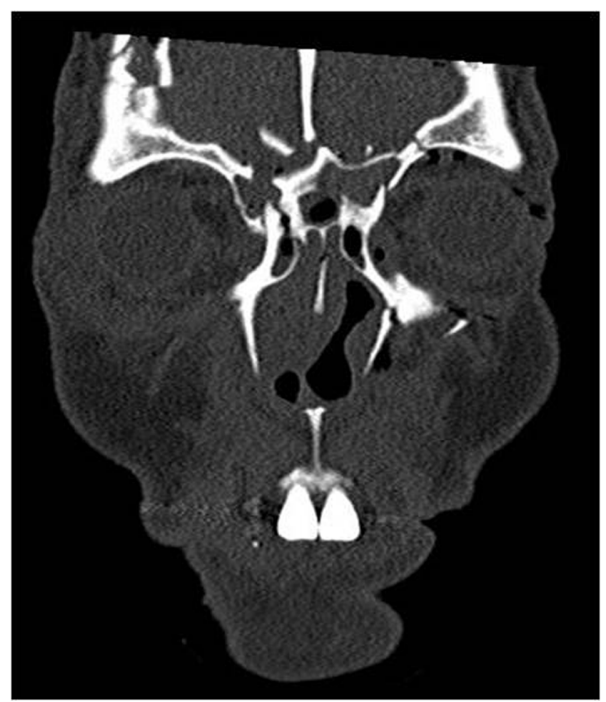

Fig. 2. Frontal sinus comminuted fracture, temporal bone fracture, nasal-orbital-ethmoidal complex. fracture, LeFort I, II, III fracture were detected.
한 두개안면복합 골절로(Fig. 2) 진단되었다.

신경외과적으로는 우측 전두부, 측두부의 경막외출혈 (epidural hemorrhage), 경막하출혈(subdural hemorrhage), 지주막하출혈(subarachinoid hemorrhage), 기뇌증(pneumocephalus), 뇌부종(diffuse brain edema)으로 진단되었다.

적절한 기도확보법에 대해 고려해 본 바, 경구, 경비 삽 관으로는 두개안면부복합 골절을 동시에 정복할 수 없고 기관 삽관술에 대한 부작용을 줄이기 위해 이하 삽관술을 계획하였고, 신경외과와 협동 수술로 이하삽관술을 통한 기도 확보 후 양측 관상절개를 통해 관혈적 정복술 및 내 고정술을 시행하였고, 두개골막 피판을 이용해 전두동의 두개화(cranialization) 술식으로 두개안면복합 골절을 치료 하였다.

이하 삽관술을 위해 통상의 경구 삽관술을 시행 후 구 강부와 이부에 소독과 방포를 시행하였다(Fig. 3). 설신경, 설하신경, 설하선관의 손상을 피하기 위해 악하부 후방부 에 하악 하연으로부터 $2 \mathrm{~cm}$ 하방에 $1.5 \mathrm{~cm}$ 가량의 절개 를 가한 후 Kelly 겸자로 광경근, 악설골근을 둔박리해서 구강 내와 개통하였다. Tube cuff를 먼저 절개선을 통해 구강외로 빼낸 후 기관내 튜브를 인공호흡단으로부터 분 리해서 구강외로 빼낸 후 cuff를 balooning한 뒤 튜브와 인

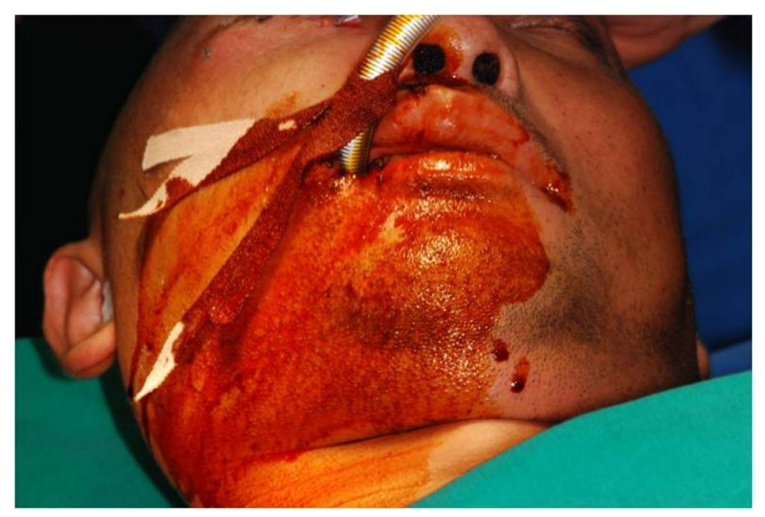

Fig. 3. After the conventional orotracheal intubation, painting and draping was done.

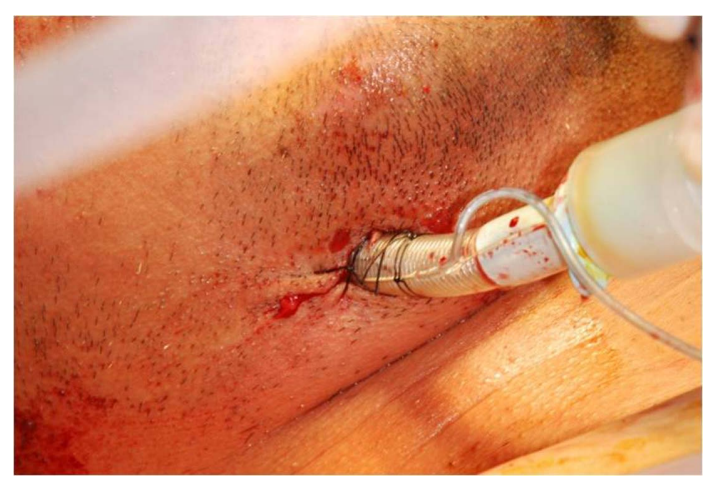

Fig. 4. Tube was maintained on submental region by 3-0 black silk. 
공호흡단을 재연결 하였다. 튜브는 3-0 black silk로 악하 부에 봉합하여 유지되었다[7](Fig. 4).

전두동의 후벽이 심하게 골절된 환자에서 두개골막 피 판을 재위치시켜 전두동 후벽을 막는 술식을 전두동의 두 개화(cranialization)라고 하는데, 본 증례에서는 전두동의 후벽의 연속성을 확립하고 뇌척수액 누출, 뇌수막염, 점액 낭종 형성을 방지하기 위하여 신경외과와 협동수술로써 전두동의 두개화를 시행하였다[8-10](Fig. 5).

수술 후 이하 삽관을 경구 삽관으로 전환해서 튜브를 가

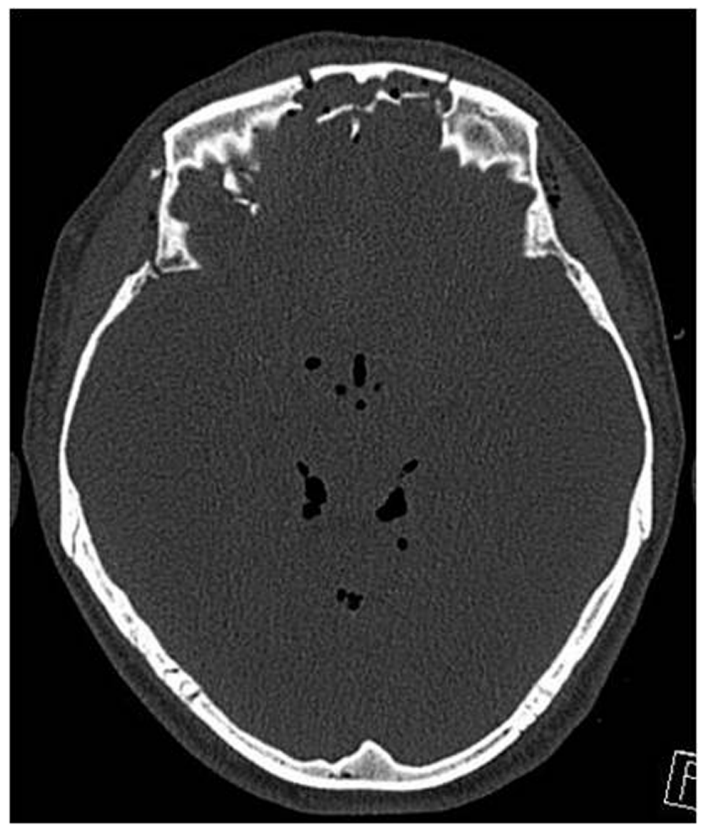

Fig. 5. Frontal sinus anterior, posterior wall fracture were detected.

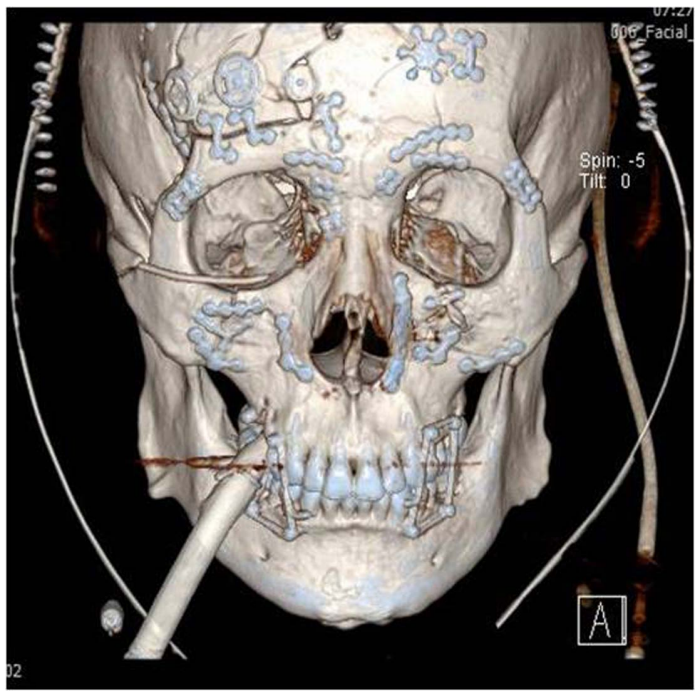

Fig. 6. 3D CT of post operation. Submental intubation was changed to orotracheal intubation and tube was changed to thinner one, tube was maintained for 1 week through right edentulous area with intermaxillary fixation.

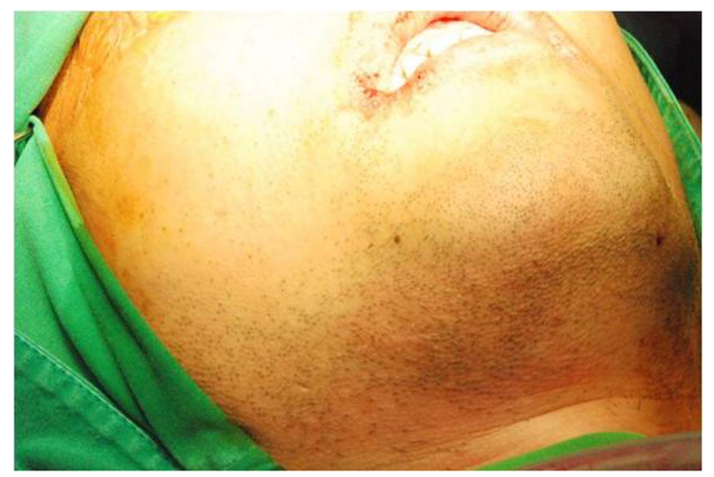

Fig. 7. Submental scar before the plate removal. The scar was relatively invisible and well tolerated by patient.

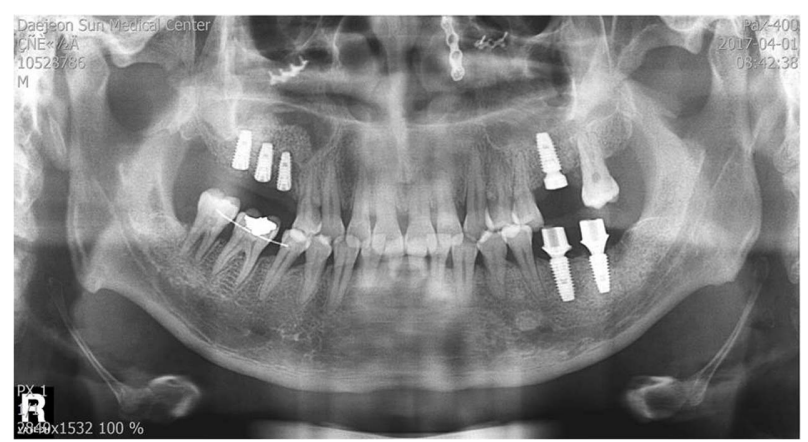

Fig. 8. Plates which were able to approach via transoral were removed and implantation was done on edentulous area.

는 것으로 교체하고, 우측의 무치악 부위를 이용하여 악간 고정과 함께 1 주일 간 유지하였고(Fig. 6), 이하삽관부위의 악하부 반흔은 거의 눈에 띄지 않았고 환자에게 용인될 만 한 수준이었다(Fig. 7). 우측 안와주위 간극의 농양은 수술 전 응급 절개 및 배농술 결과 감염과 안구증상이 해소되 었다. 안정적인 교합을 회복했고, 안면부 함몰이 교정되어 환자의 본래 안모를 회복하였다. 수술 직후 두개부, 안면 부의 감각저하는 잔존했으나 6 개월 추적검사에서는 사라 졌다. 또한 우측 안구의 외측방 운동 시 흐린 시야를 호소 하였으나, 수술 후 1 달 째 증상이 해소되었다.

본과적으로 수술 6 개월 후 골유합이 양호함을 확인하고 구강 내를 통해 소형금속판 제거술을 시행하였고, 무치악 부위에 임플란트를 이용한 보철수복을 위해 임플란트 매 식을 하였다(Fig. 8).

신경외과적으로 수술 직후 뇌수종과 뇌척수액 누출, 비 루가 잔존했으나, 6 개월의 추적검사에서 모든 증상이 해소 되었다.

\section{고 찰}

본 증례에서는 안와주위간극을 동반한 안면부 분쇄함몰 
골절 환자를 응급 절개 및 배농술을 시행한 후 이하삽관 술을 통한 관혈적 정복술 및 내고정술과 두개골막피판을 이용한 전두동의 두개화 술식으로 치료하였다.

안와주위간극 농양은 드물게 발생하지만 일반적으로 눈 꺼풀 부종, 결막 부종, 안구 돌출, 시력 저하, 안구운동 장 애, 비정상적인 동공반응 등의 증상을 동반하며, 방치되어 악화될 경우 안와 내압이 증가해서 안구 돌출로 인한 시 신경 인장, 시력상실, 감염으로 인한 독성의 신경병증, 해 면정맥동 혈전증, 뇌신경 마비에 까지 이를 수 있으므로 주의 깊은 임상 관찰과 $\mathrm{CT}$ 등을 통한 조기 진단, 신속한 항생제 치료와 적극적인 수술적 감압술을 요한다. 발생가 능한 원인으로는 상악동이나 사골동 등의 부비동 감염, 치 성감염, 측두와 농양, 구개 농양, 경막 하 혈종 등에 의해 발생하는데, 부비동염의 확산이 가장 흔한 원인으로 꼽힌 다. 직접적인 감염의 확산으로는 다수의 뼈구멍, 빼결합부, 열개부 등을 통한 확산으로, 간접적으로는 안구와 주위구 조물과 통하는 혈전성 정맥염 등을 통해 확산되며 본 증 례의 환자는 전두부의 혈종이 안와부로 확산되어 발생한 것으로 사료된다[11, 12]. 본 증례의 환자는 수상하여 본원 에 입원 후 3 일이 경과한 시점에서 부종과 $\mathrm{C}$ 반응성 단백 수치의 상승 등을 감지하고, $\mathrm{CT}$ 로 확인하여 안와주위간극 농양으로 진단하고 복합 항생요법과 함께 중환자실에서 응급 절개 및 배농술을 시행하였고, 결과적으로 시력이 완 전히 회복되었고 안구돌출이 사라졌으며 안구운동 제한 및 신경손상의 증상이 없었다.

우측 안구의 흐린 시야는 시신경관의 손상으로 시신경 이 압박된 경우 발생하며, 복시는 골절된 뼈 사이로 외안 근이 합입되거나 안와출혈로 인해 외안근이 압박되면 안 구운동장애로서 발생하는데, 우측 안와의 상벽, 내측벽의 골절을 정복함으로써 흐린 시야와 복시가 해소된 것으로 사료된다[13, 14].

두개안면부의 광범위한 골절에 대한 적절한 정복의 순 서에 대해 많은 연구가 존재한다. 아래에서 위로, 안에서 밖으로 혹은 위에서 아래로, 밖에서 안으로 같은 정복의 순서는 두개안면복합 골절의 관리를 위한 전통적인 접근 법으로 사용되어 왔다. 어떤 접근법이 더 우위에 있는지에 대한 확실한 연구는 없으며 어떠한 접근법도 모든 상황에 서 최적의 결과를 내는 것은 아니다. 대신 알려진 것에서 덜 알려진 것으로 접근하는 것이 대체적으로 정확하다 말 할 수 있다. 본 증례의 환자에서 중간, 상안면부에 LeFort I, II, III 골절, 비골안와사골 분쇄골절 등의 복잡한 골절이 존재하므로, 비교적 쉽게 정복할 수 있고 정복의 기준점으 로 삼을 만한 요소들이 많이 존재하는 상방에서부터 정복 을 시작하였고, 상하악복합체를 정복한 뒤 마지막에는 LeFort I 레벨에서 정복을 완료하여 최적의 결과를 얻을 수 있었다.
대부분의 두개안면복합 골절환자의 경우 경비, 경구 삽 관에 제한이 따른다[1]. 경비 삽관은 비골 골절의 경우 사 용이 불가능하고, 뇌수막염 발생 가능성과 두개저 골절 환 자의 경우 두개 내로 관이 들어갈 위험이 존재한다. 또한 경구 삽관은 악간고정을 방해하므로 상하악 복합체의 골 절 정복 시 안정성을 저해하므로 두개안면복합 골절 환자 에서의 사용이 제한된다[2]. 이러한 상황에서 기관절개삽 관술이 하나의 대안으로 고려되어 왔으나 기관협착, 성대 손상, 피하기종, 갑상선 손상 가능성 등의 단점이 존재한 다[3,4]. 이러한 합병증과 제한요인을 보완하고 술후 합병 증이 적은 이하삽관술에 대해 고려해 보았고, 본 증례의 환자의 기도유지법으로 선택되었다.

이하삽관술은 Altemir로부터 1986년 처음 도입된 술식 으로 광범위한 두개안면골절 환자의 기도유지에 있어서 경구, 경비, 기관절개술을 대체해 왔고, 그 후 술식 상의 변형을 거쳐왔다. 이 방법은 안전한 기도유지를 제공해주 고 구강내의 수술 공간을 방해하지 않으며 악간고정을 가 능하게 함으로써 경구, 경비 삽관, 기관절개 삽관술에 수 반되는 합병증인 비출혈, 수막염, 두개저 골절, 기관협착, 갑상선 피하기종 등을 피할 수 있다. 이하 삽관술은 술자 에게 더 나은 수술야를 제공하고 합병증을 줄일 수 있으 며 비골사골안와 복합골절과 상하악 골절이 복합된 환자 에서 기관 삽관술을 피하면서 악간 고정을 가능하게 해준 다는 장점이 있다. 이하 삽관술에 수반되는 합병증으로는 비대성 반흔, 구강-피부 누공, 점액류, 악하선 또는 설하선 도관 손상, 설신경, 하악신경 손상 등이 있다고 드물게 보고 되었고 지금까지 심각한 합병증은 보고되지 않았다. Meyer 등[7]은 이하 삽관술의 합병증으로 구강저 농양 $(8 \%)$, 비대 성 반흔(4\%)을 보고하였고, Schütz와 Hamed[15]는 이하 삽관술과 기관절개 삽관술을 비교하는 연구를 시행한 결 과 이하 삽관술이 낮은 합병증을 보였고 두개안면복합 골 절에서 기관절개 삽관술을 대체할 수 있다고 결론내렸다. Jundt 등[16]은 812명의 환자에 대한 연구결과 분석에서 $100 \%$ 의 성공률과 단지 미미한 합병증을 보고했다. 본 증 례의 환자에서는 이하 삽관술을 통한 기도확보 후 수술을 시행하고 중환자실로 전실되어 튜브를 구강내로 빼내어 통상의 경구 삽관으로 전환 후 무치악 부위를 통해 1 주일 간 유지하였고, 환자는 의식을 회복하였다. 이하 삽관술에 수반된 별다른 합병증이 관찰되지 않았고, 수술 2 개월 경 과 후 반흔이 거의 눈에 띄지 않았으며, 이하 삽관술의 결과 로 두개안면복합 골절 환자를 한번 만에 수술할 수 있었던 바, 이는 환자와 술자 모두에게 큰 도움이 되었다 $[4,5]$.

이하 삽관술은 두개안면복합 골절 환자의 수술에 이용 되는 안전하고 간단한 술식으로 경구, 경비 삽관, 기관절 개 삽관술에 수반되는 합병증을 최소화 할 수 있으며 중 안모와 하악을 동시에 정복할 수 있다는 점에서 두개안면 
Tae-Woong Ahn et al.

복합 골절환자의 치료에 있어 유용하고 예측 가능한 술식 인 바, 적극적인 고려와 사용을 권하는 바이고, 외상 뿐만 아니라 성형, 악교정 등의 구강악안면 수술 분야까지 광범 위하게 적용될 수 있을 것으로 사료된다.

\section{Conflict of Interest}

The authors declare that they have no competing interests.

\section{ORCID}

$\begin{array}{ll}\text { Tae-Woong Ahn } & 0002-0478-9390 \\ \text { Kil-Hwa Yoo } & 0002-4803-1012 \\ \text { Min-Seok Oh } & 0003-0475-4056 \\ \text { Chul-Min Park } & 0002-0806-8996 \\ \text { Seong-Hoe Yoon } & 0001-7134-4095 \\ \text { Sun-Woong Yoon } & 0002-6973-1456 \\ \text { Ka-Young Seol } & 0003-0228-322 \text { X } \\ \text { Dong-Keun Lee } & 0003-0189-1450 \\ \text { Young-Ju Park } & 0001-7373-5970 \\ \text { Dong-Soo Shin } & 0002-9158-9679\end{array}$

\section{References}

1. Biglioli F, Mortini P, Goisis M, Bardazzi A, Boari N. Submental orotracheal intubation: an alternative to tracheotomy in transfacial cranial base surgery. Skull Base 2003;13:189-195.

2. Caubi AF, Vasconcelos BC, Vasconcellos RJ, de Morais $\mathrm{HH}$, Rocha NS. Submental intubation in oral maxillofacial surgery: review of the literature and analysis of 13 cases. Med Oral Patol Oral Cir Bucal 2008;13:E197E200.

3. Kishoria N, Upadhyaya RM, Shah DM, Mahajan A. Submental intubation an alternative to tracheostomy in patients with panfacial fracture. OA Case Reports 2014;3:8.

4. Agrawal M, Kang LS. Midline submental orotracheal intubation in maxillofacial injuries: a substitute to tracheostomy where postoperative mechanical ventilation is not required. $\mathrm{J}$ Anaesthesiol Clin Pharmacol 226:498-502.

5. Altemir FH. The submental route for endotracheal intubation. A new technique. J Maxillofac Surg 1986;14:6465. doi: 10.1016/S0301-0503(86)80261-2.

6. Maclnnis E, Baig M. A modified submental approach for oral endotracheal intubation. Int J Oral Maxillofac Surg 1999;28:344-346.

7. Meyer C, Valfrey J, Kjartansdottir T, Wilk A, Barriere P. Indication for and technical refinements of submental intubation in oral and maxillofacial surgery. J Craniomaxillofac Surg 2003;31:383-388. doi: 10.1016/j.jcms. 2003.07.005.

8. Davis WE, Templer J, Parsons DS. Anatomy of the paranasal sinuses. Otolaryngol Clin North Am 1996;29:5774.

9. Day TA, Meehan R, Stucker FJ, Nanda A. Management of frontal sinus fractures with posterior table involvement: a retrospective study. J Craniomaxillofac Trauma 1998;4:6-9.

10. Donald PJ. Frontal sinus ablation b7y cranialization. Report of 21 cases. Arch Otolaryngol 1982;108:142-146.

11. Givner LB. Periorbital versus orbital cellulitis. Pediart infect Dis J 2002;21:1157-1158. doi: 10.1097/01.inf. 0000041790.79459 .80 .

12. Suneetha N, Battu RR, Thomas RK, Bosco A. Orbital abscess: management and outcome. Indian J Ophthalmol 2000;48:129-134.

13. Kim HS. Ophthalmology. 10th ed. Seoul: ilchokak Publishing; 2014. p.210-218, 292-305.

14. Jeffery JM, Glavas IP. Orbital fractures: a review. Clin ophthalmol 2011;5:95-100.

15. Schutz P, Hamed HH. Submental intubation versus tracheostomy in maxillofacial trauma patients. J Oral Maxillofac Surg 2008;1404-1409. doi: 10.1016/j.joms.2007. 12.027 .

16. Jundt JS, Cattano D, Hagberg CA, Wilson JW. Submental intubation: a literature review. Int J Oral Maxillofac Surg 2012;41:46-54. doi: 10.1016/j.ijom.2011.08.002. 